\title{
REPRESENTATIVIDADE DA DIDÁTICA NOS CURSOS DE LICENCIATURAS NOS TRABALHOS DA ANPED
}

\author{
Estela Lemos Moreira, Renata Portela Rinaldi \\ Universidade Estadual Paulista Júlio de Mesquita Filho - UNESP, Curso de Pedagogia, Presidente Prudente, SP. E-mail: \\ estelalemosm@hotmail.com. \\ Agência de fomento: $\mathrm{CNPq}$
}

\section{RESUMO}

Esta pesquisa tem como objetivo analisar o espaço da didática nos cursos de licenciatura nos trabalhos da Associação Nacional de Pós-Graduação e Pesquisa em Educação (ANPED). Foi realizada uma pesquisa bibliográfica na base de dados da ANPED, nos Grupos de Trabalhos 04 (Didática) e 19 (Educação Matemática), no período de 2011 a 2017. Sabe-se que o processo de formação inicial de professores no Ensino Superior requer, além dos conteúdos de fundamentos, conteúdos pedagógicos e práticas de ensino que apoiem o desenvolvimento da aprendizagem da docência. Todavia, reconhecemos que a formação inicial nos cursos de licenciatura, em especial na área de ciências exatas priorizou o bacharelado e as disciplinas pedagógicas ficam designadas ao final do curso. Os resultados apontam que a produção sobre o tema Didática nos cursos de licenciatura é irrisória para a importância que ela tem na formação do professor para apoiar a aprendizagem significativa do estudante.

Palavras-chave: Didática. Licenciatura. ANPED. Formação de professores. Ensino.

\section{REPRESENTATION OF DIDACTICS IN LICENCIATE COURSES IN THE ANPED TEXTS}

\begin{abstract}
This research aims to analyze the space of didactics in undergraduate courses in the work of the National Association of Graduate Studies and Research in Education (ANPED). The bibliographic search was carried out in the ANPED database, in Working Groups 04 (Didactics) and 19 (Mathematics Education), from 2011 to 2017. It is known that the process of initial teacher education in Higher Education requires, in addition to the content of the fundamentals, pedagogical contents and pedagogical practices that support the development of learning of the teacher. However, we recognize that the initial training in undergraduate courses, especially in the area of exact gave importance for baccalaureate and the pedagogical disciplines, are designated at the end of the course. The results point out that the production on the didactic theme in undergraduate courses is insignificant for the importance it has in teacher training to support meaningful student learning.
\end{abstract}

Keywords: Didactics. Licenciate. ANPED. Teacher training. Teaching 


\section{INTRODUÇÃO}

O presente artigo $^{1}$ tem como objetivo analisar o espaço da didática nos cursos de licenciaturas nos trabalhos da Associação Nacional de Pós-Graduação e Pesquisa em Educação ANPED. Para tanto, realizou levantamento de artigos completos publicados no Grupo de Trabalho da Didática (GT4) e da Educação Matemática (GT19) nas Reuniões Nacionais da Associação Nacional de Pós-Graduação e Pesquisa em Educação.

Para entender a importância da didática nos cursos de licenciatura é preciso compreender a sua dimensão enquanto disciplina que estuda o processo de ensino em sua multidimensionalidade, apoia na definição dos objetivos, conteúdos, métodos e as formas de avaliação que se combinam, de modo a criar as condições e os procedimentos para garantir aos alunos uma aprendizagem significativa. Posto isso, para Freire (1996) o conhecimento profissional do docente é um conjunto de saberes teóricos e experienciais, que se expressam em um saber agir conforme a situação e em conformidade com o contexto do indivíduo, o que remete ao termo competência.

\section{METODOLOGIA}

A pesquisa pautou-se na abordagem qualitativa que abrange o campo de estudo e possibilita caminhar em diversas variedades de pesquisas, para que entenda melhor o que está sendo pesquisado utilizando o método de investigação científica e de modo que possibilita entender o porquê de certos casos. De acordo com Alves (1991 p. 54), "[...] resultando em uma grande variedade de definições, características consideradas essenciais às estratégias de pesquisa".

Para o início de uma análise é necessário um tipo de pesquisa, ou seja, métodos essenciais para reunir as informações que precisam para a construção dos raciocínios que envolvem fato, problema e fenômeno. Um exemplo, de método investigativo é a pesquisa bibliográfica, que pode ser compreendida como:

A pesquisa bibliográfica é feita a partir do levantamento de referências teóricas já analisadas, e publicadas por meios escritos e eletrônicos, como livros, artigos científicos, páginas de web sites. Qualquer trabalho científico inicia-se com uma pesquisa bibliográfica, que permite ao pesquisador conhecer o que já se estudou sobre o assunto. Existem, porém, pesquisas científicas que se baseiam unicamente na pesquisa bibliográfica, procurando referências teóricas publicadas com o objetivo de recolher informações ou conhecimentos prévios sobre o problema a respeito do qual se procura a resposta. (FONSECA, 2002, p. 32)

Nessa perspectiva, realizamos a pesquisa na base de dados da Associação Nacional de PósGraduação e Pesquisa em Educação (ANPED), especificamente nas últimas cinco Reuniões Nacionais que ocorreram no período de 2011 a 2017, explorando os trabalhos dos GT de Didática (GT4) e Educação Matemática (GT19). A seleção dos trabalhos no GT4 foi desenvolvida a partir do descritor "licenciatura" e para o GT19 foram utilizados descritores: "didática", "licenciatura", "prática pedagógica" e "prática de ensino". Para a análise dos resultados foi necessário a leitura na integral dos textos, pois os títulos e resumos não traziam claramente o conteúdo abordado. Esse procedimento auxiliou na compreensão do objeto investigado.

\section{RESULTADOS}

Os resultados obtidos no processo de levantamento bibliográfico do GT4 nas cinco últimas Reuniões Nacionais da ANPED podem ser visualizados no Gráfico 1. Percebe-se que há uma regularidade no total de trabalhos publicados no GT nos anos de 2011, 2015 e 2017. Todavia, em 2012 nota-se um número elevado de trabalhos publicados e, por sua vez, em 2013, um número

\footnotetext{
${ }^{1}$ A pesquisa, em desenvolvimento, vincula-se a uma investigação mais ampla coordenada por Rinaldi (2018). 
reduzido de trabalhos em relação aos demais anos. Ainda, quando analisamos os trabalhos selecionados a partir do critério definido para o estudo neste GT, verifica-se que apenas $12,5 \%$ dos textos abordam na temática a licenciatura.

Gráfico 1. Comparação de trabalhos publicados na ANPED GT4 com trabalhos selecionados

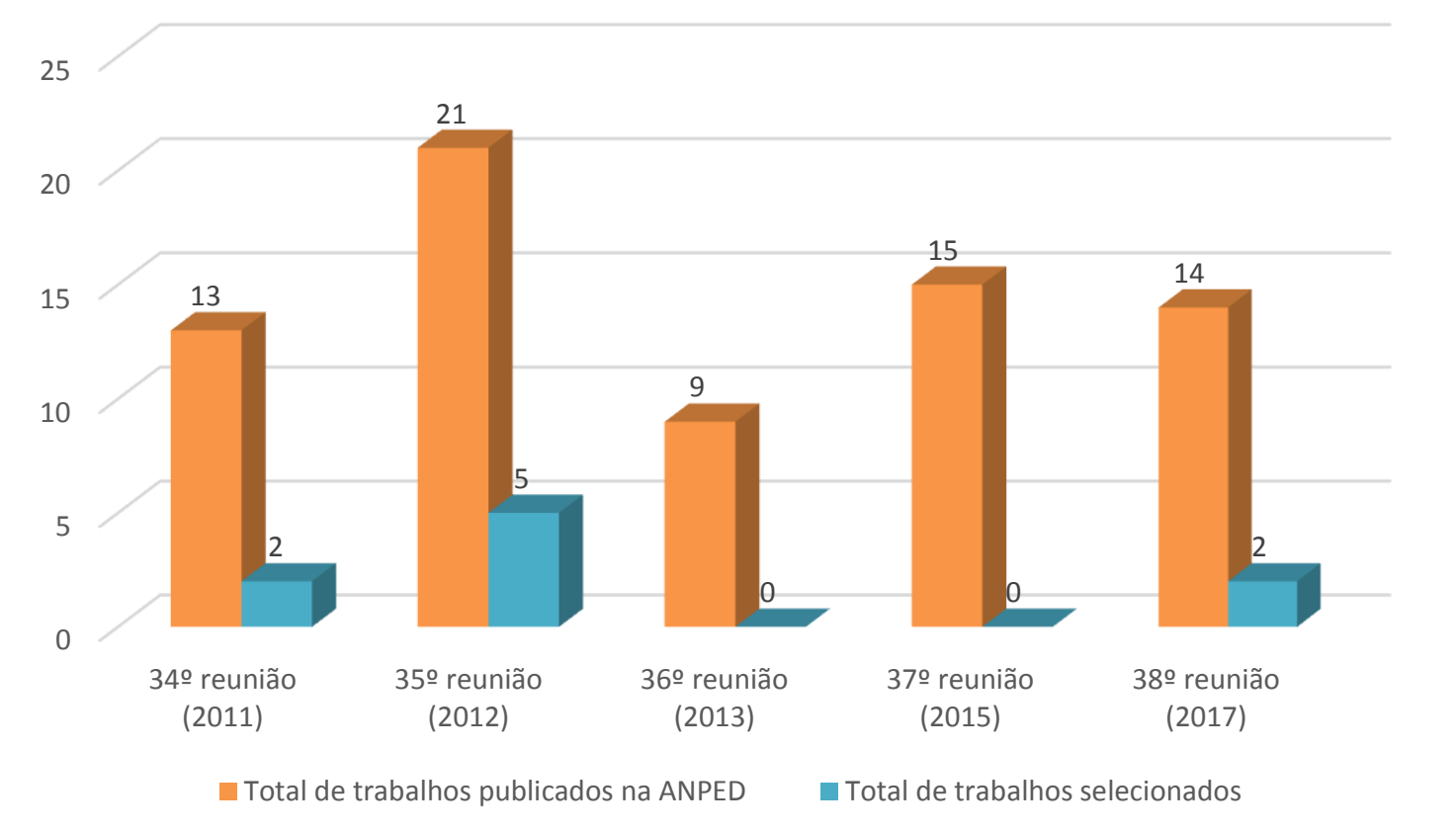

Fonte: Elaboração própria com base em levantamento bibliográfico na ANPED.

De modo geral, verifica-se a ausência de produção sobre as licenciaturas no contexto do GT de Didática. Analisando o gráfico verifica que nos anos de 2013 e 2015 não teve trabalhos publicados com a temática licenciatura, apesar de no ano anterior terem sido produzidos 5 trabalhos sobre o assunto no GT4.

No gráfico 2, apresentamos o resultado de trabalhos publicados no GT19, a partir dos critérios previamente definidos. É possível observar uma regularidade no total de trabalhos publicados pelo GT, excetuando-se o ano de 2013 que tem um aumento de $25 \%$ nas publicações. Constata-se que aproximadamente $20 \%$ dos textos publicados ao longo dos anos se relacionam ao objeto investigado, ou seja, a didática nos cursos de licenciatura. Além disso, nota-se que a partir de 2015 a publicação começa a decair ocasionando pouca produção de trabalhos relacionados a Didática. 
Gráfico 2. Comparação de total de trabalhos produzidos na ANPED com trabalhos GT19

selecionados

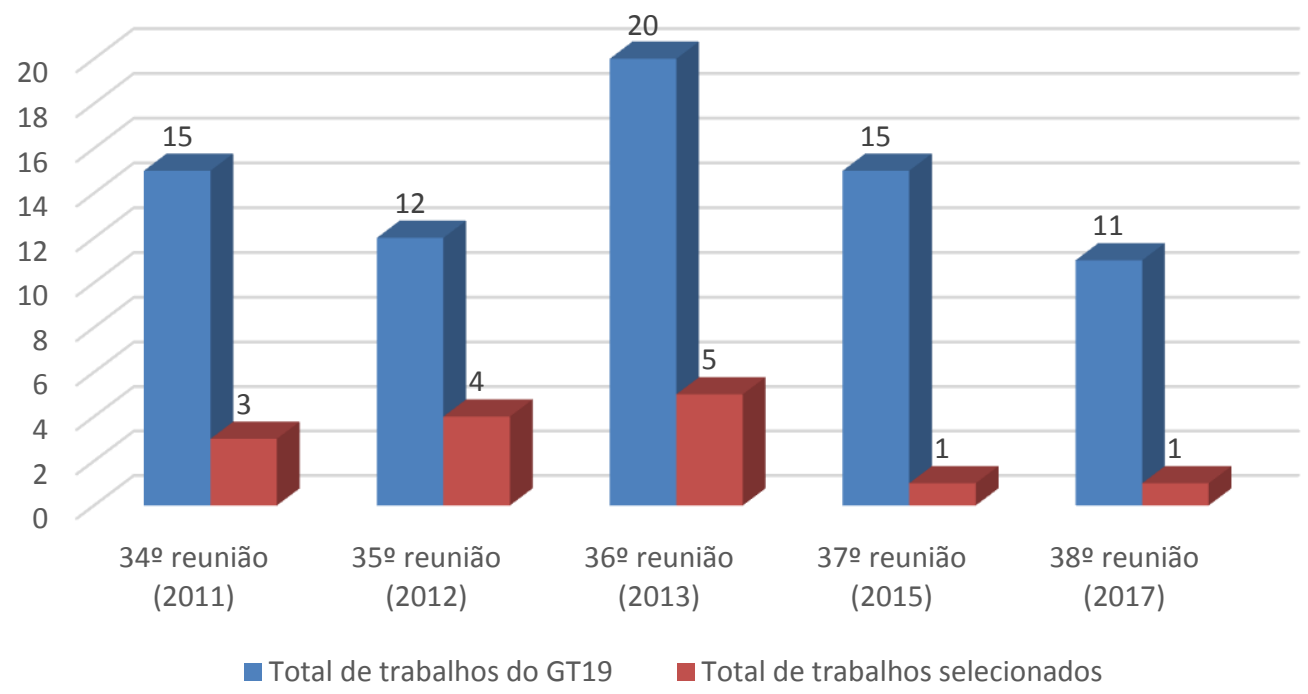

Fonte: Elaboração própria com base em levantamento bibliográfico na ANPED.

No quadro 1 é possível observar a quantidade de trabalhos publicados no GT19 por ano e de acordo com os descritores: "didática", "licenciatura", "prática pedagógica" e "prática de ensino" de acordo com os anos analisados.

Quadro 1. Sistematização dos resultados por descritor e ano pesquisado.

\begin{tabular}{|l|l|l|l|l|l|}
\hline \multirow{2}{*}{ DESCRITOR } & \multicolumn{5}{|l|}{ ANO DA REUNIÃO NACIONAL DA ANPED GT19 } \\
\cline { 2 - 7 } & $\mathbf{2 0 1 1}$ & $\mathbf{2 0 1 2}$ & $\mathbf{2 0 1 3}$ & $\mathbf{2 0 1 5}$ & $\mathbf{2 0 1 7}$ \\
\hline Didática & 2 & 0 & 0 & 1 & 0 \\
\hline Licenciatura & 0 & 1 & 1 & 0 & 1 \\
\hline Prática pedagógica & 1 & 1 & 1 & 0 & 0 \\
\hline Prática de ensino & 0 & 2 & 3 & 0 & 0 \\
\hline TOTAL & $\mathbf{3}$ & $\mathbf{4}$ & $\mathbf{5}$ & $\mathbf{1}$ & $\mathbf{1}$ \\
\hline
\end{tabular}

Fonte: Elaboração própria com base em levantamento bibliográfico na ANPED.

É possível notar que nos anos de 2011, 2012 e 2013 têm mais publicações e nos anos de 2015 e 2017 houve uma redução expressiva de trabalhos envolvendo a temática nos cursos de licenciatura. Analisando o descritor de "didática" e somente três trabalhos foram publicados durante os últimos anos de reunião da ANPED e o descritor "prática pedagógica", demonstra mais publicações, entretanto, essas publicações se concentram nos anos de 2012 e 2013.

\section{DISCUSSÃO}

A didática é considerada uma ciência que estuda os saberes da prática docente sendo ela um dos princípios para a formação do professor. Por meio dela, se desenvolvem saberes necessários à aprendizagem da docência e indispensáveis para uma prática pedagógica. Concordando com o Libâneo (2013) "[...] a didática trata da teoria geral do ensino", de acordo com Pimenta et al. (2013, p. 146).

A didática, como área da pedagogia, estuda o fenômeno ensino. As recentes modificações nos sistemas escolares e, especialmente, na área de formação de professores configuram uma "explosão didática". Sua ressignificação aponta para um balanço do ensino como prática social, das pesquisas e das transformações que têm provocado na prática social de ensinar. 
Estudar a didática nos cursos de licenciaturas não quer dizer acumular informações sobre as práticas e técnicas do processo ensino-aprendizagem, mas significa acrescentar em cada pessoa a capacidade da crítica em questionar e fazer reflexões sobre questões concebidas ao logo do processo ensino-aprendizagem. Veiga (2010, p. 58) diz que é imprescindível “[...] tornar o ensino da didática mais atraente e respaldado nos resultados das investigações envolvendo alunos em processo de formação". É preciso buscar o ensino com outras práticas sociais.

Acreditava por muito tempo que ensinar era meramente transmitir informações adquiridas pelo professor e que os alunos eram considerados seres sem luz, incapazes de pensar por conta própria. $O$ processo de ensino era considerado como uma prática mecânica de transmissão de conhecimento. Ou seja, "[...] há práticas docentes construídas sem a perspectiva pedagógica, num agir mecânico que desconsidera a construção do humano" (FRANCO, 2016, p. 535)

No entanto, o modo de ensinar do professor, requer uma adaptação ao mundo fu, com isso o processo de ensino e aprendizagem se torna recíproco e interdisciplinar, apresentando princípios essenciais e de suma importância para a formação do professor. Tais aspectos, necessitam ser considerados nos cursos de licenciatura.

\section{CONCLUSÃO}

A análise dos trabalhos das Reuniões Nacionais da ANPED nos últimos anos demonstra que há uma resistência do campo da licenciatura por se valorizar a didática como elemento essencial na formação inicial de professores. É de se preocupar com esses resultados, pois se trata de formação da capacidade pedagógica e crítica do professor em formação, para que possam ver de forma clara e objetiva a realidade do ensino de modo a possibilitar ao aluno a construção do seu próprio saber. Compreender que a educação é um processo de relevância global da sociedade significa entender que a prática pedagógica é necessária no processo de ensino, como experiência de práticas sociais que ocorrem com a finalidade de concretizar processos pedagógicos na formação do estudante.

\section{REFERÊNCIAS}

ALVES, A. J. O planejamento de pesquisas qualitativas em educação. Caderno de Pesquisa. 77 ed. São Paulo, $1991 . \quad$ Disponível em: http://publicacoes.fcc.org.br/ojs/index.php/cp/article/view/1042/1050 Acesso em: 07 de julho de 2018.

FONSECA, J. J. S. Metodologia da pesquisa científica. Fortaleza: UEC, 2002. Apostila. Disponível em: http://leg.ufpi.br/subsiteFiles/lapnex/arquivos/files/Apostila__METODOLOGIA_DA_PESQUISA\%281\%29.pdf Acesso em: 07 de julho de 2018.

FRANCO, M. A. do R. S. A prática pedagógica e docência: um olhar a partir da epistemologia do conceito. Revista Brasileira de Estudos Pedagógicos. 247 ed. v. 97. 2016. Disponível em: http://www.scielo.br/scielo.php?script=sci_arttext\&pid=S217666812016000300534\&lng=en\&nrm =iso\&tlng=pt Acesso em: 25 de julho de 2018.

FREIRE, P. Pedagogia da autonomia: saberes necessários à prática educativa. 13 ed. Rio de Janeiro: Paz e Terra, 1996.

LIBÂNEO, J. C. Didática. São Paulo: Cortez, 2013.

PIMENTA, S. G. et al. A construção da didática no GT Didática-análise de seus referenciais. Revista de Educação, v. 18, n. 52, 2013. https://doi.org/10.1590/S1413-24782013000100009. 
RINALDI, R. P. A formação de professores nos cursos de licenciatura: um estudo de caso na Faculdade de Ciências e Tecnologia da Universidade Estadual Paulista. Projeto de pesquisa. Presidente Prudente: FCT/UNESP, 2017. (mimeo)

VEIGA, I. P. A. Docência como atividade profissional. In: VEIGA, I. P. A.; D’AVILA, C. (Org.). Profissão docente: novos sentidos, novas perspectivas. 2. ed. Campinas: Papirus, 2010. 